\section{The Investigation of Flint.}

THE need for a more accurate knowledge of the dynamics of flint, as pointed out by Sir E. Ray Lankester in NaruRE of November 2I, is very obvious.

Though not so remarkable as the Savernake polished fints, yet some are to be found in the shingle for some miles both east and west of Brighton. Flints, too, with even more glaze than either of these are met with on the arable land of this district. These I assume got at some time the benefit of the vegetable ash resulting from the burning of weeds, being raked up along with them. Originally they came in the chalk from the North Downs for the use of the crops.

A caution may be useful as to what may be expected as the result of frost action. I have watched many of our Wealden sandstones for about twenty years, chiefly because of my study of the honeycomb weathering. One wall I guess at least roo yards long, on the west side of Mount Pleasant Hill, has soil behind it nearly to the top. It shows good dusty weathering along a line about $2 \mathrm{ft}$. from the pavement at the junction of the second and third courses of stone. There are, however, two very distinct patches, each two or three yards wide, where this is entirely absent. Why is this? Merely, I believe, because the places happen to get extra rain-water from two adjoining trees, and are never dry all the winter. Parts, however, which are wet and dry alternately frequently suffer.

Why, I wonder, is it that the small mammilations seen on the squared flints of the churches in the eastern counties are absent in the southern counties? Again, the Norfolk paramouara deserve more study than they have had hitherto. This year at Seaford $I$ found a 2 -in. layer of chert at the top of the chalk, which I was told is usual there. The explanation seemed to be that rain-water had taken up silica from the overlying sands and gravels. On the west of Cuckmere Haven the chalk cliffs have also remarkable rings of chert, sometimes 6 in. thick, surrounding each of the numerous pipes seen in the chalk there. These chert cylinders can be seen lying on the shore owing to the erosion by the sea. For a long time these were great puzzles, but their explanation was discovered last year by my friend, Mr. Hy. Preston, of Grantham.

Tunbridge Wells, November 23.

\section{Remarkable Formation of Ice on a Small Pond.}

Some soil (which is of a heavy nature), being required, had been dug out to a depth of about a foot. The sides and bottom were thus quite irregular. Rain-water lodged in the hole, thus forming the pond, which was about $4 \mathrm{ft}$. long, I ft. 6 in. wide, and 5 in. maximum depth; the major axis was N.E. and S.W.,

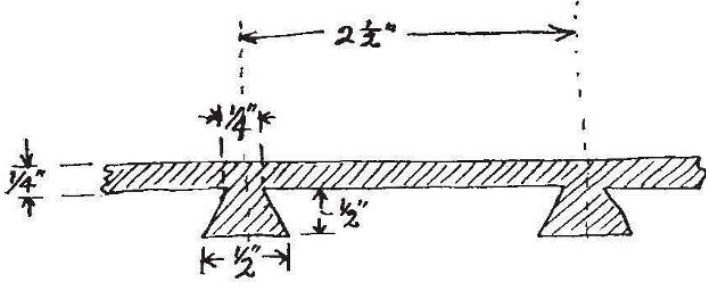

and the upper surface of the ice about 8 in. below the general level of the ground.

The ice was first noticed at 0.30 p.m. on Sunday, December I. Dark sinuous lines about $\frac{3}{8}$ in. wide and running about parallel to the major axis were plainly visible. These were seen to be due to the water below touching the ice along these lines, while the bands No. 2250 , VOL. 90] (about $2 \frac{1}{2}$ in. wide) of white between the lines were due to the water not being in contact with the ice at these portions of the under-surface. The water in the pond had gradually percolated away, and had thus left an air space of about $\frac{1}{8}$ in. between itself and the undersurface of the ice between the dark lines. On breaking the ice and getting a piece out, it was found to have the remarkable cross section shown in the sketch. The ice was quite clean and clear, and the dovetail ribs were well off the bottom of the pond. The ribs were remarkably regular in form and dimensions, and there were about six lines of them running from end to end of the pond.

There was no wind, and the frost on the grass near by was crisp, indicating that the temperature was still below $32^{\circ} \mathrm{F}$.

\section{A. S. E. Ackermann.}

\section{Anthropology at the British Association.}

I NOTICE in the article on anthropology at the British Association in Nature of November $2 \mathrm{I}$ a slight misstatement, which I should be obliged if you would correct.

The coloured photographs which I showed to the section were taken partly by my friend Mr. Mellor and myself, and the scenes represent different tombs which $\mathrm{I}$ excavated in $1903-\mathrm{O}_{5}$.

Combe Bank, near Sevenoaks, November 25.

\section{ATMOSPHERIC ELECTRICITY.}

D URING the last few years a large number of experiments and observations have been made which, instead of solving the central problem of atmospheric electricity, appear to have made it more difficult than ever. It seems desirable, therefore, that a short statement of the present position should be placed before the large body of physicists who have not yet considered this exceedingly interesting subject.

Measurements of the electrical conditions of the atmosphere have now been made over the land from north polar regions through the equator to south polar regions, over the centres of the Atlantic and South Indian Oceans, and on Samoa in the Pacific Ocean. Thus the conditions over both land and ocean areas have been investigated, and everywhere it has been found that the air is a conductor and that the potential gradient is practically the same. The result can be expressed in rather a more objective way by stating that the earth has been found to be a negatively charged sphere, of a nearly uniform surface density, surrounded by a conducting atmosphere. This, however, cannot be a complete statement of the case, for by the laws of electrostatics a charge cannot exist within a conductor, and in consequence the charge on the surface of the earth must be transferred more or less quickly to the outside of the conducting atmosphere. In spite of this, the charge on the earth's surface remains undiminished. Whence, then, comes the negative charge to make this possible? This is the chief problem of atmospheric electricity.

To make it clear that the surface of the earth does lose electricity, it will be as well to state the methods used to determine the loss. The surface of the earth is at a uniform potential, which 